\title{
La France des écrivains. Éclats d'un mythe (1945-2005), Marie-Odile André, Marc Dambre, Michel P. Schmitt (éds.)
}

\section{Laura Brignoli}

\section{(2) OpenEdition}

\section{Journals}

Édition électronique

URL : http://journals.openedition.org/studifrancesi/3869

DOI : 10.4000/studifrancesi.3869

ISSN : 2421-5856

Éditeur

Rosenberg \& Sellier

\section{Édition imprimée}

Date de publication : 1 décembre 2012

Pagination : 612-613

ISSN : 0039-2944

\section{Référence électronique}

Laura Brignoli, «La France des écrivains. Éclats d'un mythe (1945-2005), Marie-Odile André, Marc Dambre, Michel P. Schmitt (éds.) », Studi Francesi [En ligne], 168 (LVI | III) | 2012, mis en ligne le 30 novembre 2015, consulté le 07 mars 2021. URL : http://journals.openedition.org/studifrancesi/3869 ; DOI : https://doi.org/10.4000/studifrancesi.3869

Ce document a été généré automatiquement le 7 mars 2021.

\section{cc) (†) $\odot$}

Studi Francesi è distribuita con Licenza Creative Commons Attribuzione - Non commerciale - Non opere derivate 4.0 Internazionale. 


\title{
La France des écrivains. Éclats d'un mythe (1945-2005), Marie-Odile André, Marc Dambre, Michel P. Schmitt (éds.)
}

\author{
Laura Brignoli
}

\section{RÉFÉRENCE}

La France des écrivains. Éclats d'un mythe (1945-2005), Marie-Odile ANDRÉ, Marc DAMBRE, Michel P. sснмітт (éds.), Paris, Presses Sorbonne Nouvelle, 2011, pp. 291.

La mondialisation, dont on mesure toute l'envergure dans les derniers temps, a bouleversé la configuration culturelle de l'Occident et le prestige de la France, ou mieux le rôle guide de Paris, a dû céder le pas à d'autres horizons de référence. Dans ce contexte, le mythe qui s'était cristallisé autour d'une nation et d'un peuple subit d'inévitables contrecoups. Le volume en question réunit les réflexions de vingt-trois contributeurs - et non des moindres - autour de cette idée, de ses racines, de ses facettes, de son évolution. Particulièrement bien choisi, le sous-titre du volume rend compte aussi bien du scintillement du mythe que de ses fêlures. La période envisagée est déjà significative en soi et la disposition en trois groupements thématiques («Réparations, refondations», «Décompositions, fragmentations», «Disparitions, déplacements») recoupe en gros une ordonnance chronologique des objets de l'enquête qui part de Sartre et Malraux lecteurs de Michelet (J. LECARME), pour arriver à la plus immédiate contemporanéité d'écrivains tels que Bergounioux et Salvayre. Sur presque tous plane Barthes, qui reste une pierre d'achoppement pour toute volonté démystificatrice. Une courbe se dessine, qui, de l'après-guerre à nos jours, définit les contours de ce mythe que l'on ne cesse de préciser à mesure que sa légitimité est mise en question. 
2 Mais le recueil se laisse parcourir autrement, suivant d'autres lignes de force. On pourrait ainsi regrouper les auteurs autour des différentes cristallisations du mythe: idéal à protéger pour Romain Gary (N. GELAS) et Sacha Guitry (J. POIRIER), pour continuer à se nourrir de son rêve. Son appartenance à une sphère utopique distingue leur vision de la France de l'engagement qui, au contraire, se sert du mythe pour alimenter un besoin de renaissance, comme le font Char et De Gaulle (V. KeLLY): et l'on sait que le mythe gaulliste d'une France unie contre l'occupant l'emportera sur l'image charrienne d'une liberté obtenue grâce au travail souterrain de la base. C'est un sentiment national qui surgit en réaction à la guerre et à l'occupant, comme chez Mauriac, pour lequel cet objet immatériel à la beauté pure devient un corps souffrant avec la Seconde Guerre Mondiale (J. TOUZOT), ou chez Aragon (M. VASSEVIÈRE), qui voit pourtant éclater ce mythe au moment des guerres coloniales. Dans les œuvres les plus récentes les écrivains peuvent se permettre d'historiciser ce mythe, comme le fait Bergounioux (M. BARRABAND), ou même Grumberg, qui, avec son théatre, propose de refonder le mythe de la France sur la base de la solidarité (C. Douzou).

3 Mais le mythe ne résiste pas toujours: ainsi, la connotation paternaliste dont il est souvent enveloppé pousse-t-elle certains écrivains à en prendre les distances, comme le fait M. Duras, pour laquelle écrire signifie façonner sa propre identité à l'encontre des images de la France (S. CRIPPA). C'est aussi le cas des au- teurs francophones de l'Afrique du Nord qui utilisent et transgressent les stéréotypes français et maghrébins (S. BEDRANE); et surtout des égyptiens qui découvrent leur identité orientale et la défendent contre le paternalisme français qui voudrait prolonger son influence culturelle (D. LANçoN). La France coïncide souvent avec Paris, d'où émanent des valeurs historiques, culturelles et littéraires qui peuvent aisément s'ordonner autour de ses deux axes géographiques (B. CURATOLO). Mais que dans une ville prétende se concentrer toute une nation, cela ne peut satisfaire l'âme méditerranéenne de Camus, homme divisé qui ne connaît d'appartenance que linguistique (J. GUÉRIN). Plus complexe, par contre, se révèle l'assujettissement culturel des Belges, qui mettent volontiers en scène des personnages en quête d'identité, mais sans être tout à fait conscients de la source de cette constante thématique (P. DIRKX). Le mythe se désagrège chez Nimier, qui reste incapable de concevoir un développement positif face à la défaite (M. DAMBRE), et tombe sous les coups différemment ironiques de Queneau, qui se sert des lieux communs de l'histoire pour dénoncer ses mystifications (C. DE BARY), de Vialatte, qui s'en prend aux mythes les plus tenaces, liés à son histoire, son territoire, ses lieux mémorables, ses grands hommes, et aussi sa langue (A. SCHAFFNER), et de Massera, qui s'attaque aux mythes des années 80 (P. MOUGIN). Bien avant les autres, les Nouveaux Romanciers se sont aperçus que les assises de la France, à savoir son territoire, son histoire et sa littérature, ne suffisent plus à définir un concept qui n'est plus qu'une béance (J. FAERBER).

4 Que reste-t-il? Malgré tout, un idéal linguistique et littéraire. Parfois la langue est vraiment l'ultime refuge pour des écrivains de droite que l'épuration a expulsé hors des confins nationaux (F.J. AUTHIER). Mais il arrive aussi que le refus de la littérature engagée se pratique au nom d'un engagement pour défendre la «pureté» littéraire (C. COSTE), et l'on comprend finalement que le roman français connaît une voie de renaissance (R. GOLSAN).

5 Ce panorama complexe ne saurait être complet sans une réflexion au deuxième degré, comme celle d'A. LASSERRE qui interroge les paratextes de vingt histoires de la 
littérature publiées depuis 1940, pour démontrer ce qui émerge de la lecture de cet ouvrage collectif: à savoir que l'histoire littéraire est un des moyens de constitution et de promotion du mythe de l'identité nationale fondé d'abord sur le territoire et le sang, ensuite sur la francophonie. 